GEOLOGICAL SURVEY CIRCULAR 119

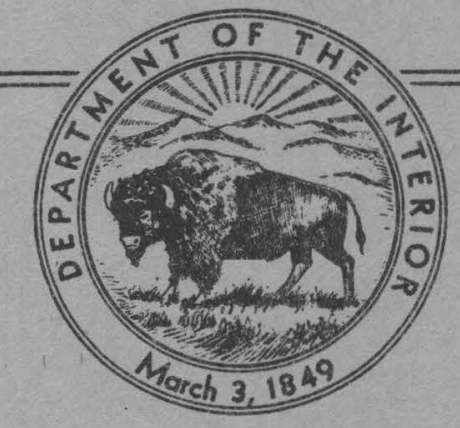

August 1951

\title{
A FIELD METHOD FOR THE DETERMINATION OF TUNGSTEN IN SOILS
}

\author{
By \\ F. N. Ward
}




\section{UNITED STATES DEPARTMENT OF THE INTERIOR Oscar L. Chapman, Secretary GEOLOGICAL SURVEY W. E. Wrather, Director}

Washington, D. C. 


\section{A FIELD METHOD FOR THE DETERMINATION OF TUNGSTEN IN SOILS}

\section{CONTENTS}

Page

Abstract. ..................

Introduction. . . . . . . . . . . . . .

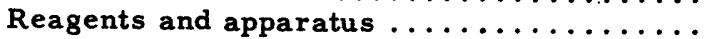

Procedures ....................

\section{ABSTRACT}

The thiocyanate-stannous chloride method for the determination of small quantities of tungsten has been modified for use on soils in geochemical prospecting. A $0.25 \mathrm{~g}$ sample of soil is fused with a modified carbonate flux in a pyrex test tube, extracted with water, and an aliquot of the aqueous extract is treated with stannous chloride and potassium thiocyanate in moderately concentrated hydrochloric acid. The tungsten thiocyanate complex ion, formed rapidly at a temperature of $90 \mathrm{C}$ to $100 \mathrm{C}$, is extracted with a small volume of isopropyl ether, and tungsten determinations are made by comparing the yellowishgreen color of the ether layer over a sample solution with that over a standard solution treated similarly. With a suitable aliquot, the field meth'od can be used on soils containing 10 to $800 \mathrm{ppm}$ of tungsten.

\section{INTRODUCTION}

A rapid semiquantitative method for determination of trace amounts of tungsten in soils was needed in connection with the field work of the Geochemical Prospecting Group of the U. S. Geological Survey. For the aid given in accomplishing this work, the author is grateful to Herbert $\mathbf{E}$. Hawkes and Lyman C. Huff, geologists, for assistance in collecting samples and to Hy Almond and Laura Reichen, chemists, for many helpful suggestions.

Colorimetric procedures are more easily adapted than other methods to the field determination of small amounts of a given element. A survey of methods currently used in the colorimetric determination of traces of tungsten shows that thiocyanate in the presence of a reducing agent like stannous chloride possesses the greatest number of advantages with respect to stability and availability of reagents and to the ease of transporting the simple apparatus required to make determinations in the field.

The thiocyanate-stannous chloride method was irst proposed for determination of tungsten by Feigl and Krumholz (1932) and was later modified
Discussion. .................. 3

References cited ................ 4

Table $1 \ldots \ldots \ldots \ldots \ldots \ldots \ldots \ldots \ldots \ldots$

to meet various needs (Fernjancix, 1934; Fer'yanchich, 1947; Sandell, 1946). Still other changes have been made in attempts to shorten the method and/or obtain better precision (Geld and Carroll, 1949; Gentry and Sherrington, 1948). Extraction of the tungsten thiocyanate complex ion with an immiscible solvent results in increased sensitivity (Sandell, 1950), and heating the reaction mixture decreases the time required to form the complex ion (Poluektov, 1941). Accordingly the proposed procedure calls for a rapid formation of the tungsten thiocyanate complex ion at a temperature of $90 \mathrm{C}$ to $95 \mathrm{C}$ followed by an isopropyl ether extraction of the complex ion from the cool aqueous solution. Tungsten determinations are made by comparing the intensity of the yellowish-green color of the ether layer over the sample solution with that obtained over a standard solution treated similarly.

\section{REAGENTS AND APPARATUS}

Flux. A mixture by weight of 5 parts sodium carbonate, 4 parts sodium chloride, and 1 part potassium nitrate, ground to pass an 80 mesh silk bolting cloth sieve, thoroughly mixed, and passed through the sieve again.

Potassium thiocyanate. A 25 percent solution. Dissolve $25 \mathrm{~g}$ of the salt in water and dilute to $100 \mathrm{ml}$.

Hydrochloric acid. Concentrated, analytical reagent grade.

Stannous chloride. Dissolve $10 \mathrm{~g} \mathrm{SnCl}_{2} \cdot 2 \mathrm{H}_{2} \mathrm{O}$ in concentrated hydrochloric acid and make up to $100 \mathrm{ml}$.

Standard tungsten solution, 0.01 percent. Solution A. Dissolve $0.09 \mathrm{~g} \mathrm{Na}_{2} \mathrm{WO}_{4} .2 \mathrm{H}_{2} \mathrm{O}$ in water and dilute to $500 \mathrm{ml}$. The solution contains 100 micrograms of tungsten per mi.

Standard tungsten solution, 0.0005 percent. Solution B. Because the concentration decreases on standing, it should be prepared daily by diluting $5 \mathrm{ml}$ of Solution $A$ with water to $100 \mathrm{ml}$ and mixing thoroughly. 
Isopropyl ether. Practical grade is suitable provided peroxides are absent. On the day during which it is to be used, shake the ether with one-tenth its volume of equal amounts of stannous chloride and potassium thiocyanate solutions. Without special packaging all dry ethers tend to form explosive peroxides on standing. To test for peroxides shake $5 \mathrm{ml}$ of ether with $5 \mathrm{ml}$ of an acidified aqueous solution of potassium iodide. If the latter shows more than a faint yellow color, due to free iodine produced by the peroxides, the ether contains appreciable quantities of peroxides and should not be used.

Water. Purify by passing tap water through one of several types of demineralizers now commercially available. The Bantarn Demineralizer manufactured by Barnstead Still and Sterilizer Company was used in this work.

Agate or Mullite mortar and pestle, outside diameter of mortar, $75 \mathrm{~mm}$.

1 sieve, 80 mesh. The sieve is assembled by placing a piece of silk bolting cloth in an aluminum holder having an outside diameter of $100 \mathrm{~mm}$.

1 aluminum receiver to fit the sieve holder.

1 camel's-hair brush, length of brush part, $18 \mathrm{~mm}$.

$1100 \mathrm{ml}$ pyrex volumetric flask with stopper.

20 pyrex culture tubes $(16 \times 150 \mathrm{~mm})$ marked at $5 \mathrm{ml}$. In addition each determination requires a culture tube not calibrated.

$1-1 \mathrm{ml}$ serological pipette calibrated in hundredths of a $\mathrm{ml}$.

1-2 $\mathrm{ml}$ serological pipette calibrated in tenths of a $\mathrm{ml}$.

2-5 $\mathrm{ml}$ serological pipettes calibrated in tenths of a $\mathrm{ml}$.

1 test tube rack holding at least 20 tubes.

Torsion balance with sensitivity $0.002 \mathrm{~g}$.

Stevens extraction sticks. (Extractor for removing soluble constituents in chemical analysis. Patent applied for by Rollin E. Stevens, U. S. Geological Survey.) Prepare the sticks from pieces of pyrex glass tubing, $170 \mathrm{~mm}$ long and $9 \mathrm{~mm}$ outside diameter as follows:

Constrict the tube at one end and at a point about $20 \mathrm{~mm}$ from the same end. Insert a plug of pyrex glass wool in the bulb formed by the two constrictions.

1 portable gasoline stove. A Coleman pocket stove used by Lakin and others (Lakin, Stevens, and Almond, 1949) is satisfactory.

1 iron rack. This rack is used to support tubes over the stove during the fusion.
1 water bath. The top of the Coleman pocket stove container filled with water to about twothirds of its capacity is an excellent water bath.

1 metal support. A round rack fitting inside the top of the Coleman pocket stove container and holding 16 tubes was used.

Cork stoppers no. 5 for the culture tubes, (16 x $150 \mathrm{~mm}$ ).

Cork stoppers no. 00 to fit the open end of the Stevens extraction sticks.

1 thermometer, $110 \mathrm{C}$.

\section{PROCEDURE}

Preparation of sample solution

Weigh $0.25 \mathrm{~g}$ of finely ground soil and transfer to a culture tube $(16 \times 150 \mathrm{~mm})$. Tap the tube gently to dislodge the sample from the sides and add $1.25 \mathrm{~g}$ of flux. Mix the sample and flux by alternately rotating and tapping the tube. Place the tube in a metal rack over the gasoline stove and allow the contents to fuse 5 to $6 \mathrm{~min}$. Rotate the tube occasionally to insure a thorough attack of the sample. After the fusion is complete, remove the tube from the rack and allow to cool. Pipette $5 \mathrm{ml}$ purified water into the tube, and place the tube in a boiling water bath. After 3 min insert a corked Stevens extraction stick into the culture tube and let the tube remain in the boiling water bath for 3 min or until air bubbles are escaping freely from the lower end of the extraction stick. Remove the culture tube from the water bath and place in a test tube rack to cool. As the solution cools, a clear filtrate of the aqueous extraction of the fused mass replaces the air displaced from the corked extraction stick at the higher temperature. Transfer a $1 \mathrm{ml}$ aliquot of the filtrate $(0.05 \mathrm{~g}$ of soil) to a clean culture tube $(16 \times 150 \mathrm{~mm})$ and add water to make the volume up to the $5 \mathrm{ml}$ mark.

\section{Preparation of standards}

Prepare a series of standard solutions by pipetting the required volume of standard solution $B$ into separate culture tubes and adding water to the $5 \mathrm{ml}$ mark.
Standard

a
b
c
d
e
f
g
h
Volume of solution $B$ required $\mathrm{ml}$
0.2
0.4
0.6
0.8
1. 0
2. 0
3. 0
4. 0

Tungsten content micrograms
Determination of tungsten:

Add $4 \mathrm{ml}$ stannous chloride and $0.5 \mathrm{ml}$ potassium thiocyanate reagents to the sample solution and to each standard solution. Place the tubes in 
a water bath maintained at a temperature of $90 \mathrm{C}$ to $95 \mathrm{C}$ for $5 \mathrm{~min}$ or until one observes a moderate evolution of hydrogen sulfide. If the altitude causes the water to boil below the specified temperature, allow the tubes to remain in the water bath until hydrogen sulfide evolves freely. Remove the tubes from the water bath, cool, add $0.5 \mathrm{ml}$ potassium thiocyanate reagent and 0.3 $\mathrm{ml}$ isopropyl ether. Insert a clean cork into the tube and shake $5 \mathrm{sec}$ to extract the tungsten thiocyanate complex ion into the ether. Compare the intensity of the yellowish-green color of the ether layer over the sample with that obtained over the standard solution. If the color of the ether layer over the sample is amber instead of yellowishgreen, add about $5 \mathrm{ml}$ of concentrated hydrochloric acid and shake to bleach the amber color. Since a small amount of the immiscible solvent is lost during this process, add an additional $0.1 \mathrm{ml}$ isopropyl ether in order to make valid comparisons.

Multiply. the number of micrograms of tungsten found in the aliquot by 20 to convert the results to parts per million. The procedure is suitable for soils containing from 20 to 400 ppm of tungsten; but, if one adjusts the aliquot, the lower limit can be decreased to $10 \mathrm{ppm}$ and the upper limit increased to a point where the quantity of tungsten present can be determined more conveniently by other field methods (North and Grimaldi, 1946).

After the analysis is complete, wash and retain the calibrated culture tube and extraction stick for future use. Destroy the tube used for the fusion as the action of the flux makes further use impracticable.

\section{DISCUSSION}

The Stevens extraction stick is used to effect a rapid filtration of the aqueous extract of the fused mass under field conditions. In practice the open end of the tube is corked and the extraction stick is inserted in the culture tube containing the hot aqueous extract. Air in the stick is forced through the plugged end until equilibrium is attained or the culture tube is removed from the boiling water bath. After a few minutes the culture tube containing the aqueous extract and stick is removed from the boiling water bath and set aside to cool. Upon cooling, a partial vacuum is formed within the tube and causes the aqueous extract to filter through the glass plug. Thus, from a practical standpoint, the fused mass is extracted and filtered in one operation.

Since the pyrex culture tube allows a limited amount of heat transfer, and, under field conditions, the Coleman stove provides less heat than an ordinary laboratory burner, sodium carbonate alone cannot be used as a flux in the proposed procedure. The melting point is too high. However, finely ground sodium carbonate mixed with an equal quantity of finely ground sodium chloride fuses at a temperature attainable with the gasoline stove under field conditions. Subsequently, a small amount of potassium nitrate was added to provide an oxidizing flux. The resulting flux, a mixture by weight of 5 parts sodium carbonate, 4 parts sodium chloride, and 1 part potassium nitrate possesses the advantages of a carbonate flux and at the same time fuses at a temperature low enough for field use.

The carbonate fusion followed by an aqueous extraction separates tungsten from iron, titanium, and other elements which form insoluble hydroxides. Littie is known about the retention of tungsten by the leached residue; but since losses due to coprecipitation are usually smaller in a fusion procedure than in a precipitation procedure (Sandell, 1946), one can expect negligible losses of tungsten during the preparation of the sample solution.

Since rhenium occurs only to the extent of $0.001 \mathrm{ppm}$ in the earth's crust (Goldschmidt, 1937) and the isopropyl ether does not extract small amounts of tantalum, uranium, phosphorus, and boron, interferences due to these elements are unlikely. Moreover, under the stipulated conditions, vanadium in amounts as great as 1000 micrograms imparts no color to the organic layer. Both fluoride and nitrate tend to bleach the yellow color of the tungsten thiocyanate ion. However, the amount of fluorine in soils is not appreciable and the amount of nitrate present remains constant because the quantity added in the flux is much greater than that reported in soils.

Large amounts of copper react with thiocyanate to form the white insoluble cuprous thiocyanate, but the reaction apparently causes no interference in the method.

On the basis of the results obtained in our laboratory, molybdenum interference is the exception rather than the rule. Only 2 of 15 soil samples analyzed in our laboratory contained enough molybdenum in the final aliquot to impart an amber color to the isopropyl ether layer. Since the intensity of the color of the molybdenum thiocyanate complex ion is considerably less than that of the tungsten thiocyanate ion (Grimaldi and North, 1943; Sandell, 1950), and since tungsten is 4 to 5 times as abundant as molybdenum in the earth's crust (Goldschmidt, 1937), these results are not surprising. The adaptation of a method to field use requires the omission of unnecessary steps, particularly those using additional or larger quantities of reagents; therefore, except for the rare but easily discernible case of molybdenum interference, concentrated hydrochloric acid is not added to the sample solution (See p. ). With standard solutions containing 10 micrograms each of tungsten and molybdenum, the yellowish-green color of the tungsten thiocyanate complex ion was readily observed after the addition of concentrated hydrochloric acid and a thorough mixing of the solution.

At the higher temperature used in the proposed field method, the stannous chloride also reduces the potassium thiocyanate causing evolution of hydrogen sulfide. If this reduction is allowed to continue more than 2 or 3 minutes, black stannous sulfide is precipitated. In order to avoid this reaction and other possible side reactions, the analyst can allow the complex tungsten thiocyanate ion to form at room temperature with different standing periods. Within the limits of experimental error, the same results were obtained on 5 soil samples (a) by allowing the reaction to take 
place rapidly at a high temperature, (b) by allowing the sample solution plus reagents to stand at room temperature for 2 hours, shaking occasionally, or (c) by allowing the sample solution plus reagents to stand at room temperature overnight, shaking immediately before making color intensity comparisons. In all cases the color intensities obtained over sample solutions are compared with those obtained over standard solutions treated similarly.

In order to test the usefulness of the method, several soils were analyzed by an accepted colorimetric laboratory procedure using the same reaction (Grimaldi and North, 1943), and by the proposed field method. The results are shown in table I. The values obtained by the field method are in good agreement with those obtained by the accepted procedure.

The proposed method is simple and capable of intensive application. The reagents and equipment are commercially available and both are easily fitted in a small carrying case. With little experience the analyst can determine tungsten on 25 or more soil samples per day with sufficient accuracy for programs of geochemical prospecting as well as other research programs requiring a rapid accumulation of data.

\section{REFERENCES CITED}

Feigl, F., and Krumholz, P., 1932, Colorimetric determination of small amounts of tungsten: Zeitschr. angew. Chemie, vol. 45, pp. 674-5.

Fernjancic, S., 1934, Rapid method for deter mining small quantities of tungsten in ores: Zeitschr. anal. Chemie, vol. 97, pp. 332-4.

Fer'yanchich, F. A., 1947, Colorimetric determination of tungsten in minerals in the pres- ence of arsenic, antimony, molybdenum, titanium, and phosphorous: Zavodskaya Lab., vol. 13, pp. $668-76$.

Geld, Isidore and Carroll, Jacob, 1949, Colorimetric determination of columbium and tungsten in high-temperature alloys: Anal. Chemistry, vol. 21, pp. 1098-1101.

Gentry, C. H. R., and Sherrington, L. G., 1948 , Photometric determination of tungsten: Analyst, vol. 73, pp. 57-67.

Goldschmidt, V. M., 1937, Geochemische Verteilungsgesetze der Elemente 9, Die Mengenverhältnisse der Elemente und der Atom-Arten: Norske vidensk-akad. Oslo Skr., Mat. -naturw. Klasse 4, p. 148.

Grimaldi, F. S., and North, Victor, 1943, Determination of tungsten in low-grade tungsten ores: Ind. Eng. Chemistry, Anal. Ed., vol. 15, pp. $652-4$.

Lakin, H. W. , Stevens, R. E., and Almond, Hy, 1949, Field Method for the determination of zinc in soils: Econ. Geology, vol. 44, pp. 296-306.

North, Victor and Grimaldi, F. S. , 1946, A field test for the detection and estimation of tungsten: U. S. Geological Survey Bull. 950, pp. 129-31.

Poluektov, N. S., 1941, Colorimetric determination of tungsten: Zavodskaya Lab., vol. 10, pp. $92-3$

Sandel1, E. B., 1946, Determination of tungsten in silicate rocks: Ind. Eng. Chemistry, Anal. Ed., vol. 18, pp. 163-7.

Sandell, E. B., 1950, Colorimetric determination of traces of metals, 2d ed. , 673 pp. , New York, Interscience Publishers.

Table I. --Determination of tungsten in soils

\begin{tabular}{|c|c|c|c|}
\hline \multirow[b]{2}{*}{ Sample No. } & \multirow[b]{2}{*}{ Location } & \multicolumn{2}{|c|}{ Tungsten found, $\mathrm{ppm}$} \\
\hline & & $\begin{array}{l}\text { Laboratory } \\
\text { method }\end{array}$ & $\begin{array}{c}\text { Field } \\
\text { method }\end{array}$ \\
\hline $\begin{array}{r}1 \\
2 \\
3 \\
4 \\
5 \\
6 \\
7 \\
8 \\
9 \\
10 \\
11 \\
12 \\
13 \\
14 \\
15\end{array}$ & 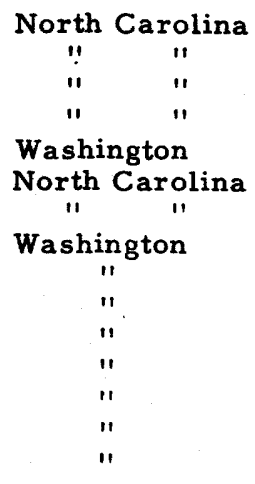 & $\begin{array}{r}0 \\
8 \\
10 \\
20 \\
28 \\
40 \\
90 \\
108 \\
114 \\
260 \\
325 \\
500 \\
1200 \\
1400 \\
3300\end{array}$ & $\begin{array}{r}10 \\
10 \\
10 \\
10 \\
60 \\
40 \\
50 \\
60 \\
90 \\
200 \\
300 \\
600 \\
1000 \\
1000 \\
2500\end{array}$ \\
\hline
\end{tabular}

